\title{
Histopathology and Morphometric Analysis of the Internal Mammary Artery to Study the Incidence of Atherosclerosis and Its Associated Risk Factors
}

\author{
Shilpa Suresh ${ }^{1}$, S. R. Kalpana ${ }^{2}$, H. V. Jayanth Kumar'1, Sumithra Selvam³, Kumsi Sreedhar ${ }^{1}$ \\ ${ }^{1}$ Department of Cardiothoracic Surgery, Sri Jayadeva Institute of Cardiovascular Sciences and Research, Bengaluru, India \\ ${ }^{2}$ Department of Pathology, Sri Jayadeva Institute of Cardiovascular Sciences and Research, Bengaluru, India \\ ${ }^{3}$ Department of Biostatistics, St. Johns Research Institute, Bengaluru, India \\ Email: shilpa.suresh@gmail.com
}

How to cite this paper: Suresh, S., Kalpana, S.R., Jayanth Kumar, H.V., Selvam, S. and Sreedhar, K. (2020) Histopathology and Morphometric Analysis of the Internal Mammary Artery to Study the Incidence of Atherosclerosis and Its Associated Risk Factors. World Journal of Cardiovascular Surgery, 10, 67-74.

https://doi.org/10.4236/wjcs.2020.106009

Received: February 5, 2020

Accepted: June 13, 2020

Published: June 16, 2020

Copyright $\odot 2020$ by author(s) and Scientific Research Publishing Inc. This work is licensed under the Creative Commons Attribution International License (CC BY 4.0).

http://creativecommons.org/licenses/by/4.0/

\section{(c) (i) Open Access}

\begin{abstract}
Background: The left internal mammary artery (IMA) is widely used as a conduit for coronary revascularization. The incidence of atherosclerosis is known to be lower in the IMA than in the coronary artery. The aim of this study was to evaluate the reliability of the use of the distal section of the IMA as an anastomotic site for bypass grafting and morphometric studies of IMA in patients with proven coronary artery disease and their associated risk factors. Methods: Patients who underwent Coronary Artery Bypass Graft (CABG) from June 2010 to November 2012 were chosen in this retrospective study and the discarded distal segments of the internal mammary artery were analyzed. The potential risk factors for atherosclerosis considered were age, sex, diabetes mellitus, history of cigarette smoking, hypertension and hypercholesterolemia. The samples were analyzed for the degree of intimal thickening and atherosclerosis by calculating the percentage of Luminal Narrowing, Intimal Thickness Index (ITI) and Intima-to-Media Ratio (IMR). Results: There were seven cases of intimal hyperplasia and two cases of focal medial and intimal hyperplasia with fatty streak and no cases of atherosclerosis and medial calcification. ITI was higher in males when compared to females. There was a strong relationship between IMR and smokers when compared to nonsmokers. Conclusion: In our study, when ITI was used as the dependent variable, diabetes was the most important factor. When IMR was used, the strongest predictor was hypercholesterolemia. There was a strong relationship between IMR and smokers when compared to nonsmokers.
\end{abstract}




\section{Keywords}

Atherosclerosis, Calcification, Coronary Artery Bypass Graft, Intimal Hyperplasia

\section{Introduction}

For over a decade, the survival benefit of the use of the left internal mammary artery (IMA) for patients undergoing coronary re-vascularization has been well established. Therefore, in particular in the more recent period, an expanded use of the IMA in coronary artery bypass grafting (CABG) has been reported [1] [2]. In spite of the similarity of arterial hemodynamics, intrathoracic respiratory pressure changes, biochemical environment and cross-sectional diameter, the incidence of atherosclerosis is known to be lower in IMA than in coronary artery [3]. Several angiographic [4] [5] [6] and histopathologic studies [7] [8] have shown that the IMA is relatively free from major occlusive disease. The specific histologic, ultrastructural and histochemical properties of the IMA may protect it from atherosclerosis [5] [9]. However, because of variability in structure and reactivity along its downstream course, selection of the anastomotic site at the distal end of this artery may have some disadvantages. He et al. have shown that the distal section of the IMA has the highest reactivity along its full length and it is the part where the spasm may develop [10]. Van Son et al. have found that the degree of intimal thickening in the IMA is greater at its distal segment [11]. Diffuse intimal thickening may represent an early phase of the atherosclerotic process.

In order to evaluate the reliability of the use of the distal section of the IMA as an anastomotic site for bypass grafting with regard to its susceptibility to develop intimal changes or atherosclerosis, histopathology and morphometric studies of IMA in patients with proven coronary artery disease were performed and the associated risk factors were studied.

\section{Materials and Methods}

Patient characteristics: Patients undergoing CABG from June 2010 to November 2012 were chosen. The vessels used in this study were the discarded distal segments of the internal mammary artery. Samples from a total number of 130 consecutive patients were obtained out of which 100 were analysed. 30 samples were not suitable for morphometric analysis due to the following reasons-samples with inadequate LIMA length to get a good cross sectional cut of the LIMA and samples with clamping artefacts. The potential risk factors for atherosclerosis considered were age, sex, diabetes mellitus, history of cigarette smoking, hypertension and hypercholesterolemia.

Histopathology: The arterial segments were processed and paraffin blocks 
were created. Sections were cut and stained with hematoxylin-eosin and Verhoeff-Van Gieson elastin (VVG) stain was used. A single pathologist blinded to the clinical data examined the slides. In this study, three methods were used to evaluate the degree of intimal thickening and arteriosclerosis:

1) Percentage of Luminal Narrowing

2) Intimal Thickness Index (ITI)

3) Intima-to-Media Ratio (IMR).

The severity of disease was calculated from the most severely diseased section using the following formulae:

Percentage of luminal narrowing $=100 \times$ intimal area/internal elastic lamina area

ITI $=$ intimal area/medial area

IMR = width of intima at maximal intimal thickness/width of media at maximal intimal thickness.

Morphometric evaluation: Morphometric evaluation was accomplished by a computerized image analysis system. The system comprised of

- Microscope - AxioLab (Carl Zeiss)

- Camera - Axiocam ICC1

- PC - Microsoft Windows XP SP2

- Application Software - Axiovision 4.8.2

For morphometric analysis, VVG stained sections were used. The sections were screened and fields were selected. The field indicating maximum intimal thickness was captured at the magnification of $4 \times$. The intimal (um) and medial thickness (um) were measured. The specimens were then graded as follows (adapted from Kobayashi and colleagues) [12]:

- Grade 0: Insignificant/no lesion

- Grade 1: intima-to-media ratio lesser than 0.25

- Grade 2: intima-to-media ratio greater than 0.25 but less than or equal to 0.5

- Grade 3: intima-to-media ratio greater than 0.5 but less than or equal to 0.75

- Grade 4: intima-to-media ratio greater than 0.75

Microscopic morphology: Vessels were recorded as normal if there was no cellular or stromal tissue between the endothelium and the internal elastic lamina. Vessels with any fibromyointimal proliferation between the endothelium and internal elastic lamina were recorded as indicating intimal hyperplasia. An atherosclerotic lesion was defined by the presence of intimal lipid lying free as cholesterol clefts or in aggregates of foamy macrophages.

\section{Statistical Analysis}

Descriptive statistics were reported as mean with standard deviation for the continuous variables, number and percentages for the categorical variables. Independent $t$ test was used to compare the \% Luminal narrowing, ITI and IMR between gender, the presence of diabetes, hypertension, dyslipidaemia, smokers and alcoholic. $\mathrm{P}$ value less than $5 \%$ was considered statistically significant. All the analyses were done using SPSS version 18.0 software. 


\section{Results}

Histopathology: There were 7 cases of intimal hyperplasia and two cases of focal medial and intimal hyperplasia with fatty streak and no cases of atherosclerosis and medial calcification. No Grade 4 (>75\% Luminal Narrowing) lesions were found (Figure 1).

Morphometric analysis:

Morphometric measurements $(n=100)$ were done and percentage of luminal narrowing, intimal thickness index and intima to media ratio was calculated.

There was no significant difference in the percentage of luminal narrowing, ITI and IMR between the presence of DM, HTN, dyslipidaemia and alcoholic. The results indicate minimal relationship between known risk factors and extent of atherosclerosis in the ITA. The median IMR among smoker and non-smokers were 0.25 and 0.17 respectively. The median IMR in smokers was higher as compared to non-smokers $(\mathrm{p}=0.05)$. The median IMR among males was significantly higher as compared to females $(\mathrm{p}=0.03)$.

\section{Discussion}

Histopathology:

In our study, we found no cases of atherosclerosis and intimal hyperplasia was found in 5 cases. In 1976, Kay et al. examined 215 ITAs from routine post-mortem examinations and found a $>25 \%$ reduction in lumen diameter in $4.2 \%$ of ITAs. [13] No patient had a $>50 \%$ narrowing (Table 2). Other post-mortem and angiographic studies have reported an incidence rate of ITA atheroslcerosis ranging from $2.4 \%$ to $5 \%$ [14] [15].

Morphometric analysis:

Percentage of luminal narrowing is a measure of severity of intimal thickening, including atherosclerosis. The area rather than the thickness of the intima is measured to allow accurate evaluation of eccentric or irregular disease. It is presumed to be a useful parameter for comparing intimal thickening in different vascular beds. The ITI and IMR are alternative methods of comparing intimal disease in different vascular beds. ITI is more accurate because it uses areas of intima and media rather than width.

Risk factors:

Smoking, hypercholesterolemia and hypertension are common risk factors for coronary artery disease, but these factors appear to have different effects on arteries in different locations of the body [16] [17] [18]. In our study, there was no significant difference in the percentage of luminal narrowing, ITI and IMR between the presence of diabetes, hypertension, dyslipidemia and alcholics (Table 1) [16]. The results in our study indicate minimal relationship between known risk factors and extent of atherosclerosis in the ITA. Kay et al. found that intimal thickening of the ITA correlated with age, hypertension, diabetes and PVD [13].

In our study, median IMR in smokers was higher than in non smokers (Table 2) [19]. In a study by Permyos et al., comparative histopathology of radial artery 
versus ITA was done and risk factors for intimal hyperplasia in ITA were age and smoking (Table 3).

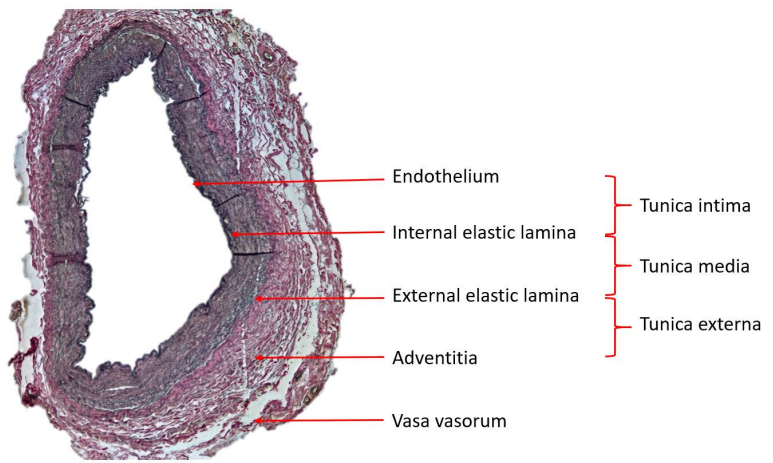

Figure 1. VVG (veroeff Vangieson) stained cut section of IMA.

Table 1. Summary of the clinical features of the study subjects.

\begin{tabular}{cc}
\hline Characteristics & Frequency \\
Sex & 92 \\
Males & 8 \\
Females & \\
Smoker & 24 \\
Present & 76 \\
Absent & \\
Diabetes & 39 \\
Present & 61 \\
Absent & \\
Hypertension & 44 \\
Present & 56 \\
Absent & \\
Severity index & \\
\% LN & $18.9 \pm 13.0$ \\
& $15.2(10.5,23.5)$ \\
ITI & $0.16 \pm 0.10$ \\
IMR & $0.15(0.11,0.19)$ \\
& $0.23 \pm 0.17$ \\
\end{tabular}

Reported as number; ${ }^{*}$-mean $\pm \mathrm{SD}$, median $\left(25^{\text {th }}, 75^{\text {th }}\right.$ percentiles $)$.

Table 2. Comparison of morphometric measurements by gender.

\begin{tabular}{cccc}
\hline & Female & Male & P value \\
& $\mathrm{N}=9$ & $\mathrm{~N}=89$ & \\
\hline \multirow{2}{*}{ \% Luminal narrowing } & $23.7 \pm 28.3$ & $18.7 \pm 11.2$ & 0.66 \\
& $11.7(10.1,26.5)$ & $15.7(10.5,23.5)$ & \\
ITI & $0.25 \pm 0.30$ & $0.15 \pm 0.06$ & 0.84 \\
& $0.16(0.09,0.21)$ & $0.14(0.12,0.19)$ & \\
IMR & $0.14 \pm 0.10$ & $0.23 \pm 0.18$ & 0.03 \\
& $(0.07,0.16)$ & $0.20(0.12,0.28)$ & \\
\hline
\end{tabular}

P value using Mann-Whitney U test. 
Table 3. Comparison of morphometric measurements by smoking status.

\begin{tabular}{cccc}
\hline & $\begin{array}{c}\text { Smokers } \\
23\end{array}$ & $\begin{array}{c}\text { Non-Smokers } \\
76\end{array}$ & P value \\
\hline \% Luminal narrowing & $15.0(10.2,27.4)$ & $15.5(10.5,22.3)$ & 0.67 \\
ITI & $0.14(0.11,0.19)$ & $0.15(0.11,0.19)$ & 0.74 \\
IMR & $0.25(0.13,0.33)$ & $0.17(0.12,0.26)$ & 0.05 \\
\hline
\end{tabular}

$P$ value using Mann-Whitney $\mathrm{U}$ test.

In our study, the median IMR among males was significantly higher as compared to females (Table 1). In a study by Dignan et al., the influence of age and sex on human ITA size and reactivity was studied and the data suggested that IMAs from women and the elderly were not more susceptible to reduction in flow due to smaller size [20] [21] [22]. In regard to female gender, no study has yet reported a significant association with intimal hyperplasia or other structural changes in ITA.

\section{Conclusion}

In our study, there was no significant difference in the percentage of luminal narrowing, ITI and IMR between the presence of DM, HTN, dyslipidaemia and alcoholics. The median IMR among males was significantly higher as compared to females. However, the limitation in our study is the limited sample size and we would need a larger study for us to derive more accurate results. In the future, as a continuation to our study, we are planning a follow-up of these patients and perform a check angiogram to identify the flow in the internal mammary artery and collaborate the findings with this study.

\section{Conflicts of Interest}

The authors declare no conflicts of interest regarding the publication of this paper.

\section{References}

[1] Barner, H.B. (1994) Use of the Internal Thoracic Artery: Simple, Complex, or with a Backup? The Annals of Thoracic Surgery, 57, 8-9.

https://doi.org/10.1016/0003-4975(94)90356-5

[2] Loop, F.D., Lytle, B.W., Cosgrove, D.M., Stewart, R.W., Goormastic, M., Williams, G.W., Golding, L.A., Gill, C.C., Taylor, P.C., Sheldon, W.C. and Proudfit, W.L. (1986) Influence of the Internal-Mammary-Artery Graft on 10-Year Survival and Other Cardiac Events. The New England Journal of Medicine, 314, 6. https://doi.org/10.1056/NEJM198601023140101

[3] Sims, F.H. (1983) A Comparison of Coronary and Internal Mammary Arteries and Implications of the Results in the Etiology of Arteriosclerosis. American Heart Journal, 105, 560-556. https://doi.org/10.1016/0002-8703(83)90478-7

[4] Krine, R., Deng, M.C., Heinrich, K.W., Sons, H. and Krian, A. (1990) Semiselective Angiography of the Internal Mammary Artery as a Preparation for Coronary Bypass Surgery. American Journal of Cardiology, 66, 377-378. 
https://doi.org/10.1016/0002-9149(90)90855-U

[5] Singh, R.N. (1983) Atherosclerosis and the Internal Mammary Artery. CardioVascular and Interventional Radiology, 6, 72-76. https://doi.org/10.1007/BF02552775

[6] Barner, H.B., Swarts, M.T., Mudd, J.G. and Tyras, D. (1982) Late Patency of the Internal Mammary Artery as a Coronary Bypass Conduit. The Annals of Thoracic Surgery, 34, 408-412. https://doi.org/10.1016/S0003-4975(10)61402-6

[7] Hadjiisky, R., Bourdillon, M.C. and Grosgo-geat, Y. (1991) Enzyme Histochemical Expressions of Smooth Muscle Cell Modulation in Arterial Development, Hypertension and Remodeling. Cellular and Molecular Biology, 37, 531-540.

[8] Mestres, C.A., Rives, A., Igual, A., Vehi, C. and Murtra, M. (1986) Atherosclerosis of the Internal Mammary Artery. Histo-Pathological Analysis and Implications on Its Results in Coronary Artery Bypass Graft Surgery. The Thoracic and Cardiovascular Surgeon, 34, 356-358. https://doi.org/10.1055/s-2007-1022172

[9] Chaikhouni, A., Crawford, F.A., Kochel, P.J., Olanoff, L.S. and Halushka, P.V. (1986) Human Internal Mammary Artery Produces More Prostacyclin than Saphenous Vein. The Journal of Thoracic and Cardiovascular Surgery, 92, 88-91. https://doi.org/10.1016/S0022-5223(19)35935-5

[10] He, G.-W., Acuff, T.E., Yang, C.-Q., Ryan, W.H. and Mack, M.J. (1994) Middle and Proximal Sections of the Human Internal Mammary Artery Are Not "Passive Conduits". Journal of Thoracic and Cardiovascular Surgery, 108, 741-746. https://doi.org/10.1016/S0022-5223(94)70302-7

[11] Van Son, J.A.M., Smedts, F., De Wilde, P.C.M., Pijls, N.H.J., Wong-Alcala, L., Kubat, K., Tavilla, G. and Lacquet, L.K. (1993) Histological Study of the Internal Mammary Artery with Emphasis on Its Suitability as a Coronary Artery Bypass Graft. The Annals of Thoracic Surgery, 55, 106-113. https://doi.org/10.1016/0003-4975(93)90483-X

[12] Kobayashi, H., Kitamura, S., Kawachi, K., et al. (1993) A Pathological and Biochemical Study of Arteriosclerosis in the Internal Thoracic Artery, a Vessel Commonly Used as a Graft in Coronary Artery Bypass Surgery. Surgery Today, 23, 697-703. https://doi.org/10.1007/BF00311708

[13] Kay, H.R., Korns, M.E., Flemma, R.J., Tector, A.J. and Lepley, D. (1976) Atherosclerosis of the Internal Mammary Artery. The Annals of Thoracic Surgery, 21, 504-507. https://doi.org/10.1016/S0003-4975(10)63917-3

[14] Singh, R.N. (1983) Atherosclerosis and the Internal Mammary Arteries. CardioVascular and Interventional Radiology, 6, 72-77. https://doi.org/10.1007/BF02552775

[15] Sisto, T. and Isola, J. (1989) Incidence of Atherosclerosis in the Internal Mammary Artery. The Annals of Thoracic Surgery, 47, 884-886. https://doi.org/10.1016/0003-4975(89)90027-1

[16] Salonen, J.T. and Salonen, R. (1994) Risk Factors for Carotid and Femoral Atherosclerosis in Hypercholesterolemic Men. Journal of Internal Medicine, 236, 561-566. https://doi.org/10.1111/j.1365-2796.1994.tb00846.x

[17] Salonene, J.T., Puska, P. and Kottke, T.E. (1981) Smoking, Blood Pressure ANS Serum Cholesterol as Risk Factors of Acute Myocardial Infarction and Death among Men in Eastern Finland. European Heart Journal, 2, 365-373. https://doi.org/10.1093/oxfordjournals.eurheartj.a061221

[18] Salonen, J.T., Puska, P., Tuomilehto, J. and Homan, K. (1982) Relation of Blood Pressure, Serum Lipids and Smoking to the Risk of Cerebral Stroke: A Longitudinal Study in Eastern Finland. Stroke, 13, 327-333. 
https://doi.org/10.1161/01.STR.13.3.327

[19] Ruengsakulrach, P., Sinclair, R., Komeda, M., Raman, J., Gordon, I. and Buxton, B. (1999) Comparative Histopathology of Radial Artery versus Internal Thoracic Artery and Risk Factors for Development of Internal Hyperplasia and Atherosclerosis. Circulation, 100, II-139-II-144. https://doi.org/10.1161/01.CIR.100.suppl_2.II-139

[20] Dignan, R.J., Yeh, T., Dyke, C.M., Lutz, H.A. and Wechsler, A.S. (1992) The Influence of Age and Sex on Human Internal Mammary Artery Size and Reactivity. The Annals of Thoracic Surgery, 53, 792-797.

[21] Ozkan, S., Akay, T.H., Gultekin, B., Aslim, E., Arslan, A., Ozdemir, B.H., et al. (2007) Atherosclerosis of Radial and Internal Thoracic Arteries Used in Coronary Bypass: Atherosclerosis in Arterial Grafts. Journal of Cardiac Surgery, 22, 385-389. https://doi.org/10.1111/j.1540-8191.2007.00431.x

[22] Borovic, M.L., Borovic, S., Marinkovic-Eric, J., Todorovic, V., Puskas, N., Kocica, M., et al. (2013) A Comprehensive Morphometric Analysis of the Internal Thoracic Artery with Emphasis on Age, Gender and Left-to-Right Specific Differences. Histology and Histopathology, 28, 1299-1314. 